BMJ Surgery, Interventions, \& Health Technologies

\section{How to tie dangerous surgical knots: easily. Can we avoid this?}

To cite: Drabble E, Spanopoulou S, Sioka E, et al. How to tie dangerous surgical knots: easily. Can we avoid this? BMJ Surg Interv Health Technologies 2021;3:e000091. doi:10.1136/ bmjsit-2021-000091

Received 13 April 2021 Accepted 23 June 2021

Check for updates

(C) Author(s) (or their employer(s)) 2021. Re-use permitted under CC BY-NC. No commercial re-use. See rights and permissions. Published by BMJ.

${ }^{1}$ Clinical lead BSS course RCS England, Consultant Surgeon (retired), University ofPlymouth Hospitals NHS Trust, Plymouth, UK

${ }^{2}$ Royal College of Surgeons of England, London, UK

${ }^{3}$ Surgical Directorate, University of Plymouth Hospitals NHS Trust, Derriford Hospital, PlymouthPL6, Greece

${ }^{4}$ Department of Plastic Surgery, Hopital Universitaire Henri

Mondor, Paris, France

${ }^{5}$ Department of Surgery, IASO

Hospital Thessalias, Larissa,

Greece

${ }^{6}$ Surgical clinic B, General

Hospital Georgios Gennimatas,

Athens, Greece

${ }^{7}$ Department of General Surgery, University Hospital of Larissa,

Mezourlo, Greece

${ }^{8}$ Department of

Otorhinolaryngology, University

Hospital of Larissa, Mezourlo,

Greece

${ }^{9}$ Department of Statistical

Analysis, University of Plymouth,

Plymouth, UK

Correspondence to

Dr Eric Drabble;

ericdrabble@live.com

\section{ABSTRACT}

Objective Secure knots are essential in all areas of surgical, medical and veterinary practice. Our hypothesis was that technique of formation of each layer of a surgical knot was important to its security.

Design Equal numbers of knots were tied, by each of three groups, using three techniques, for each of four suture materials; a standard flat reef knot (FRK), knots tied under tension (TK) and knots laid without appropriate hand crossing (NHCK). Each knot technique was performed reproducibly, and tested by distraction with increasing force, till each material broke or the knot separated completely.

Setting Temporary knot tying laboratory.

Materials The suture materials were, 2/0 polyglactin 910 (Vicryl), 3/0 polydioxanone, 4/0 poliglecaprone 25 (Monocryl) and 1 nylon (Ethilon).

Participants Three groups comprised, a senior surgeon, a resident surgeon and three medical students.

Outcome measures Proportion of each knot type that slipped, degree of slippage and length of suture held in loop secured by each knot type.

Results $20 \%$ of FRK tied with all suture materials slipped; all knots tied with the other two techniques, with all materials, slipped, TK (100\%) and NHCK (100\%). The quantitative degree of slip was significantly less for FRK (mean 6.3\%-, 95\% Cl 2.2\% to 10.4\%) than for TK (mean $312 \%, 95 \% \mathrm{Cl} 280.0 \%$ to $344.0 \%$ ) and NHCK (mean $113.0 \%,-95 \% \mathrm{Cl} 94.3 \%$ to $131.0 \%$ ).

The mean length of suture in loops held within (FRK mean $25.1 \mathrm{~mm} 95 \% \mathrm{Cl} 24.2$ to $26.0 \mathrm{~mm}$ ) was significantly greater than mean lengths held by the other techniques (TK mean $17.0 \mathrm{~mm}, 95 \% \mathrm{Cl} 16.3$ to $17.7 \mathrm{~mm}$ ), (NHCK mean $16.3 \mathrm{~mm}, 95 \% \mathrm{Cl} 15.9$ to $16.7 \mathrm{~mm}$ ). The latter two types of knot may have tightened more than anticipated, in comparison to FRK, with potential undue tissue tension. Conclusion Meticulous technique of knot tying is essential for secure knots, appropriate tissue tension and the security of anastomoses and haemostasis effected.

\section{INTRODUCTION}

Knot tying is an essential basic practical skill required by all surgeons, veterinary surgeons and any clinician engaged in patient procedures, in all medical as well as surgical specialties. Secure knots that will not slip or fail, are essential for safe surgical and interventional practice, ensuring haemostasis, the integrity of anastomoses, secure and appropriate

\section{Key messages}

What is already known about this subject?

- The study design was simple, with equal numbers of knots tied for each technique, and for each material.

What are the new findings?

- Only a small number of participants tied knots, limiting any assessment to the effect of the knot tying technique. No inference could be drawn regarding the effect of seniority of participant.

How might these results affect future research or surgical practice?

- A relatively small number of knots were tied with each of the materials limiting more detailed assessment of the effect of the suture material and size on knot security, or whether material and size had any significant influence.

apposition of wounds, and security of interventional devices. A number of papers have investigated what type of knot could be considered to be best, even looking at the addition of surgical glue to aid security. ${ }^{1-43}$ What has not been assessed, in objective detail, is the influence of the actual technique of formation of each layer of the knot on the integrity and security of a square surgical knot, rather than what type of knot.

The security of a knot tied with any material relies on the friction between layers of material applied to make the knot, and the greater the lengths of both sections of suture brought firmly together to entwine and hold against each other, the greater the friction and security of the knot. ${ }^{1445}$

The advent of more modern suture materials, and more monofilament sutures, has led us to apply more layers of material, or more 'throws', to create secure knots as these materials are considered to be more slippery than older materials, and the current recommendation is that we should apply at least six layers of material when securing knots with a monofilament material, such as polypropylene or nylon. ${ }^{2} 3132146-49$ However, the number of 'throws' or layers of suture laid in 
each knot could be irrelevant if the technique with which the knot is formed is inadequate. ${ }^{14}$ 36-38

This initial study assessed the impact of technique of knot formation on the integrity and security of standard surgical reef knots, tied using four commonly used suture materials of varying thickness, or strength, and performed by three grades of surgeon, a senior consultant, a surgical trainee who had previously been taught on the Intercollegiate Basic Surgical Skills course, ${ }^{50}$ and three medical students. The intention was to determine the influence of technique on the integrity of surgical reef knots, the most commonly used form of knot in surgical procedures; size and strength of the suture material, and experience of the operating surgeon were considered to be less likely to be important. ${ }^{15262830334046-485152535455}$

\section{MATERIALS AND METHODS}

Three techniques of tying a surgical reef knot were determined and designed so that each participating surgeon would tie each of the three knots in a reproducible manner common to all participating surgeon groups. Each knot was tied using a needle holder, with instrument tying techniques to facilitate reproducibility between all three surgeon groups.

The first technique was creation of a flat reef knot (FRK) with each layer of the knot, or 'throw', formed with equal and opposite movements of the hands and needle holder, so that each hand crossed each other at an angle of 180 degrees, placing each layer of the knot at precisely the same level, or plane, as the knot itself, ensuring that equal amounts of each end of the suture material used were placed and intertwined in a flat horizontal layer (figure 1).

The second technique was designed to mimic a method where some surgeons maintain tension on a knot to try and prevent it potentially loosening during tying, such as that employed by some when tying a knot at depth (TK). This is usually performed by keeping one end of the suture material stiff to maintain tension on the knot,

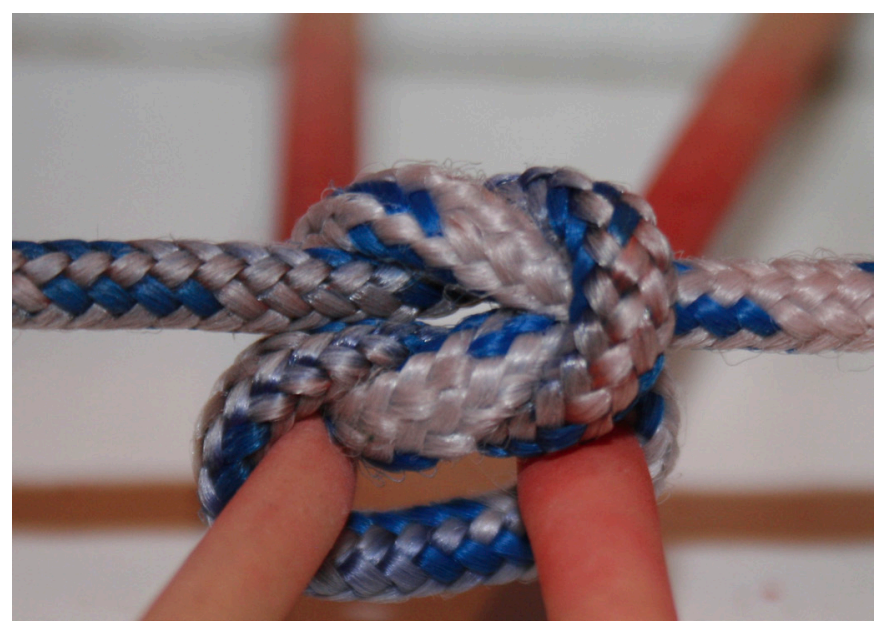

Figure 1 Flat reef knot with equal lengths of both ends of suture in knot.

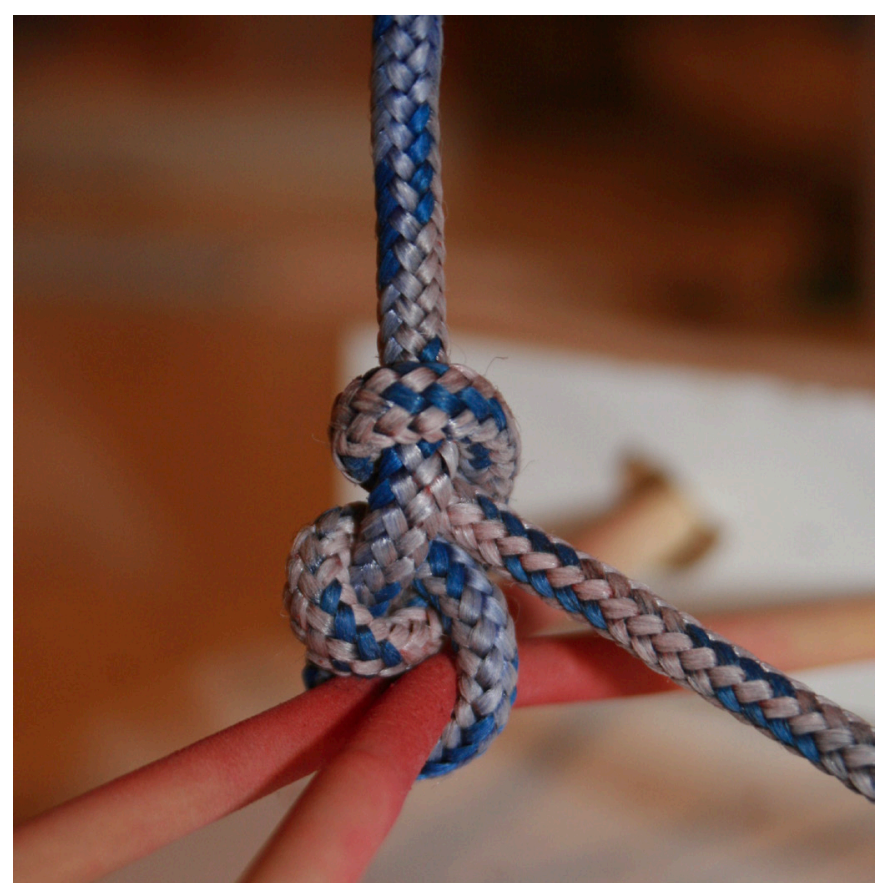

Figure 2 Knot tied under tension producing inadvertent slip knot.

while forming the knot predominantly with the other end. This was performed in this study by keeping one end of the suture tense in a vertical plane, but moving the other end of the suture material producing equal and opposite movements across the knot so that each hand movement was at an angle of 180 degrees to the other, but only with one hand rather than both (figure 2). All layers were placed in the same horizontal plane.

The third technique was designed to mimic a type of mistake where the operating surgeons forgets, or neglects, to remember to cross their hands with each layer of the knot so they neglect to produce equal and opposite hand movements with each layer of the knot (knots laid without appropriate hand crossing, NHCK). Each surgeon would diligently form each layer of the knot as if they intended to perform equal and opposite movements of the hand, alternating formation of layers that should be laid in a downward direction with those that should be laid in the opposite upward direction, but each layer was completed with one hand always moving in a downward direction towards the surgeon (figures 3 and 4). All layers of the knot were placed in one horizontal plane perpendicular to the knot.

A senior consultant surgeon, a junior surgeon and a group of three medical students, each tied ten knots of each of the three techniques, using four suture materials of different calibres, three monofilament, $4 / 0$ poliglecaprone 25 (Monocryl), 3/0 polydioxanone (PDS) and no.1 nylon (Ethilon) and one braided suture, 2/0 polyglactin 910 (Vicryl), provided by Ethicon Greece. All performed these knots at one centre, on one study day. Each knot was tied across an apparatus designed to test its strength and integrity, analogous to that used in other 


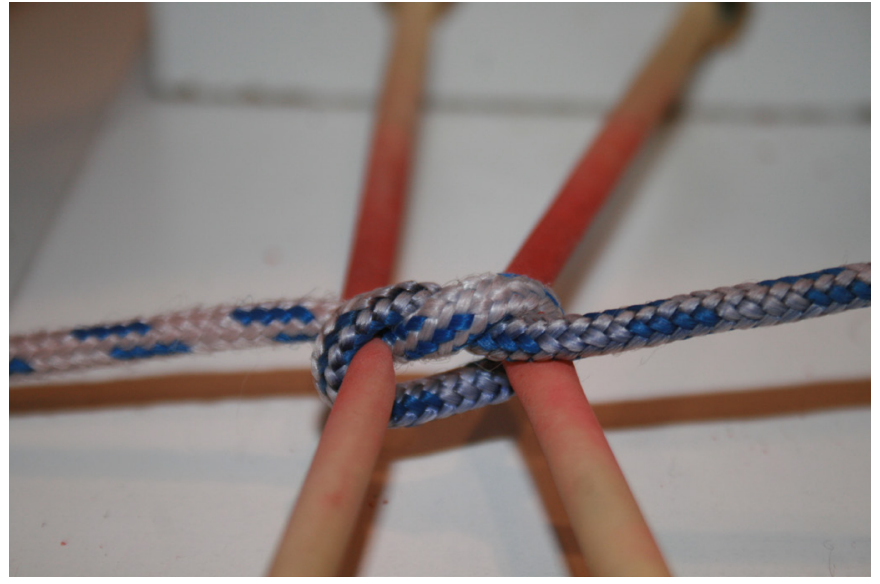

Figure 3 First layer of knot.

studies on strength of knots. ${ }^{22} 285657$ This consisted of a chain attached to a fixed clamp which was then tied to a spring loaded weight measuring device that allowed incremental increases in the weight force applied to the knot and measurement of it (figure 5).

Once the knot was created, each end of the knot was marked with an indelible marker, rapid drying Tippex marker for 2/0 polyglactin 910 (Vicryl), 3/0 PDS and No. 1 nylon (Ethilon) sutures, and blue indelible dye for 4/0 poliglecaprone 25 (Monocryl) sutures. The pressure applied to each knot was increased incrementally till one of three final events occurred; the knot breaks completely with no evidence of slippage of the knot prior to rupture, slippage of the knot and then rupture of the suture, or complete failure of the knot as it slips and completely unravels. Each outcome was recorded, and each suture was photographed following its final outcome. The force at which each knot broke or slipped was measured. The degree by which a knot slipped when tested, was determined by measuring the amount of suture material that appeared, between the indelible markers applied to each end of the suture as it met the knot prior to testing, and the knot itself following application of force (figures 6

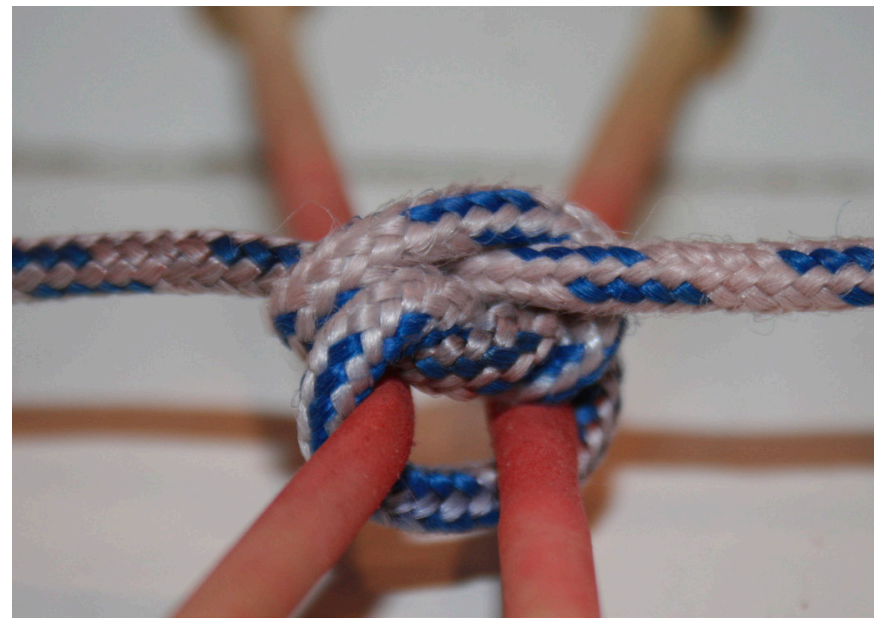

Figure 4 Second layer of knot when operator failed to cross-hands appropriately.

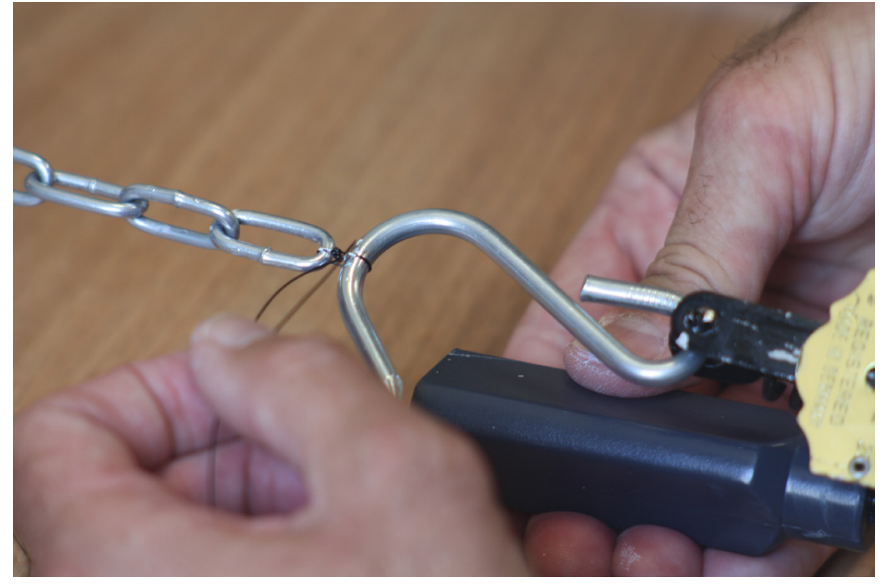

Figure 5 Suture tied across metal rings ready for distraction and testing.

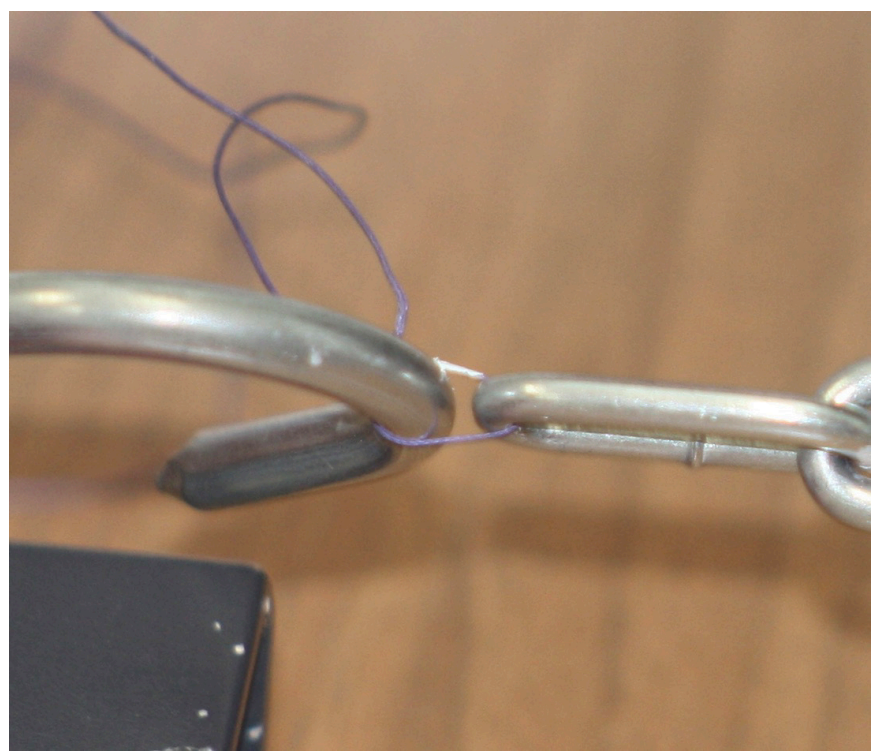

Figure 6 Suture being distracted in test bed, length of suture held in loop within test bed.

and 7). The amount of material that appeared at either end of the knot following application of sufficient force to break it, or cause it unravel, was measured using digital

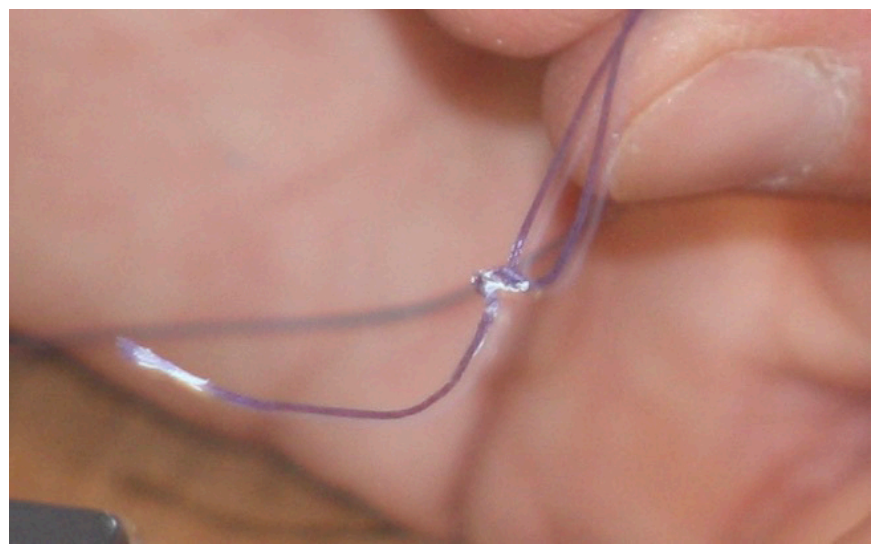

Figure 7 Minimal slippage of knot prior to rupture of loop in suture by distraction in test bed. 
Table 1 Number of knots tied with each method, and proportion of knots tied with each method that slipped on testing, mean length of slippage $\mathrm{MM}$, and proportional increase in amount of suture material held within knot post slippage, for each method and $95 \% \mathrm{Cl}$

\begin{tabular}{|c|c|c|c|c|c|c|}
\hline $\begin{array}{l}\text { Method of } \\
\text { formation of } \\
\text { square reef knot }\end{array}$ & $\begin{array}{l}\text { No of knots } \\
\text { tied }\end{array}$ & $\begin{array}{l}\text { No and } \\
\text { proportion (\%) } \\
\text { of knots that } \\
\text { slipped on } \\
\text { testing }\end{array}$ & $\begin{array}{l}\text { Mean length of } \\
\text { slippage, mm } \\
\text { and proportional } \\
\text { degree of } \\
\text { slippage, (\%), } \\
\text { recorded for knot } \\
\text { method }\end{array}$ & $\begin{array}{l}\text { 95\% lower } \mathrm{Cl} \text {, } \\
\mathrm{mm}(\%)\end{array}$ & $\begin{array}{l}\text { 95\% upper } \mathrm{Cl} \text {, } \\
\mathrm{mm}(\%)\end{array}$ & $\begin{array}{l}\text { Median } \\
\text { length of } \\
\text { slippage } \\
\mathrm{mm}\end{array}$ \\
\hline Flat reef knot & 120 & 24 (20) & $1.2(6.3)$ & $0.5(2.2)$ & $2.0(10.4)$ & 0.0 \\
\hline $\begin{array}{l}\text { Knot tied under } \\
\text { tension }\end{array}$ & 120 & 120 (100) & $50.6(312.0)$ & $45.9(280.0)$ & $55.4(344.0)$ & 51.5 \\
\hline
\end{tabular}

callipers, compared with the length of suture material included in the loop held by the original knot, and expressed as a percentage proportion of the length of suture included in that loop.

Figures 6 and 7 (Demonstrating length of material incorporated in loop held by the knot, prior to breakage on testing, and minimal slippage as demonstrated by suture material beyond white marker on left side (figure 7) post rupture suture.)

The force required to break each knot, or cause it to slip and unravel, was measured using the spring loaded weight measuring device and expressed in kilograms force.

The results obtained were tested for statistical significance by determining their means and $95 \%$ CI.

\section{RESULTS}

Equal numbers of each type of knot technique were tied (120) (table 1), equal numbers of knots by each surgeon group (120) (table 1), and equal amounts of each suture material were used with each technique (90) (table 2). Each surgeon group tied 10 knots of each of the three knot types, with each of the four suture materials, producing a total of 360 knots for testing and assessment.

\section{Knot slippage}

Twenty per cent of knots tied with all suture materials, by all surgeon groups, using an FRK technique with both hands crossing at 180 degrees to each other, and all layers of the knot laid in the same plane as the knot, subsequently slipped to some degree on testing. $100 \%$ of knots tied with one hand maintaining tension on the knot (TK), and $100 \%$ of those tied with one hand always moving in a downward direction (NHCK), slipped. In addition, the mean degree of slippage, as measured as a proportional increase in the amount of material that appeared between the indelible markers and the knot itself, or as the mean length of extra material measured in $\mathrm{mm}$, following formation of an FRK $(6.3 \% 95 \%$ CI $2.2 \%$ to $10.4 \%)(1.2 \mathrm{~mm}, 95 \%$ CI 0.5 to $2.0 \mathrm{~mm})$, was significantly less than the mean degrees of slippage of knots formed with the other two techniques, with one hand holding the knot under tension (TK) $(312.0 \%, 95 \%$ CI $280.3 \%$ to $343.7 \%)(50.6 \mathrm{~mm}, 95 \%$ CI 45.9 to $55.4 \mathrm{~mm})$, and with one hand always moving in a one direction, rather than

Table 2 Number of knots tied with each suture material, proportion of each that slipped on testing, mean degree of slippage in $\mathrm{MM}$ and proportional increase in amount of suture material held within each knot after slippage (\%), for each suture material and $95 \% \mathrm{Cl}$

\begin{tabular}{|c|c|c|c|c|c|c|}
\hline Suture material & $\begin{array}{l}\text { No of knots } \\
\text { tied with } \\
\text { suture } \\
\text { material }\end{array}$ & $\begin{array}{l}\text { No and } \\
\text { proportion } \\
\text { of knots } \\
\text { that } \\
\text { slipped n } \\
(\%)\end{array}$ & $\begin{array}{l}\text { Mean length of slippage } \\
\text { of knots tied with } \\
\text { each suture material } \\
\text { mm, and proportional } \\
\text { increase in length of } \\
\text { suture material held } \\
\text { within knot post slip } \\
\text { (\%) }\end{array}$ & $\begin{array}{l}\text { Lower } \\
95 \% \mathrm{Cl} \text { of } \\
\text { mean length } \\
\text { and mean } \\
\text { proportion of } \\
\text { slippage } \mathrm{mm} \\
\text { (\%) }\end{array}$ & $\begin{array}{l}\text { Upper } \\
95 \% \mathrm{Cl} \text { of } \\
\text { mean length } \\
\text { and mean } \\
\text { proportion of } \\
\text { slippage } \mathrm{mm} \\
(\%)\end{array}$ & $\begin{array}{l}\text { Median } \\
\text { slippage } \\
\mathrm{mm}\end{array}$ \\
\hline $3 / 0$ polydioxanone & 90 & $63(70.0 \%)$ & $19.1(119.0)$ & $13.6(83.0)$ & 24.5 (154.0) & 8.6 \\
\hline 1 nylon (Ethilon) & 90 & $70(77.8 \%)$ & 34.9 (213.0) & 28.6 (173.0) & $41.2(252.0)$ & 27.7 \\
\hline
\end{tabular}


Slip length by knot tying method

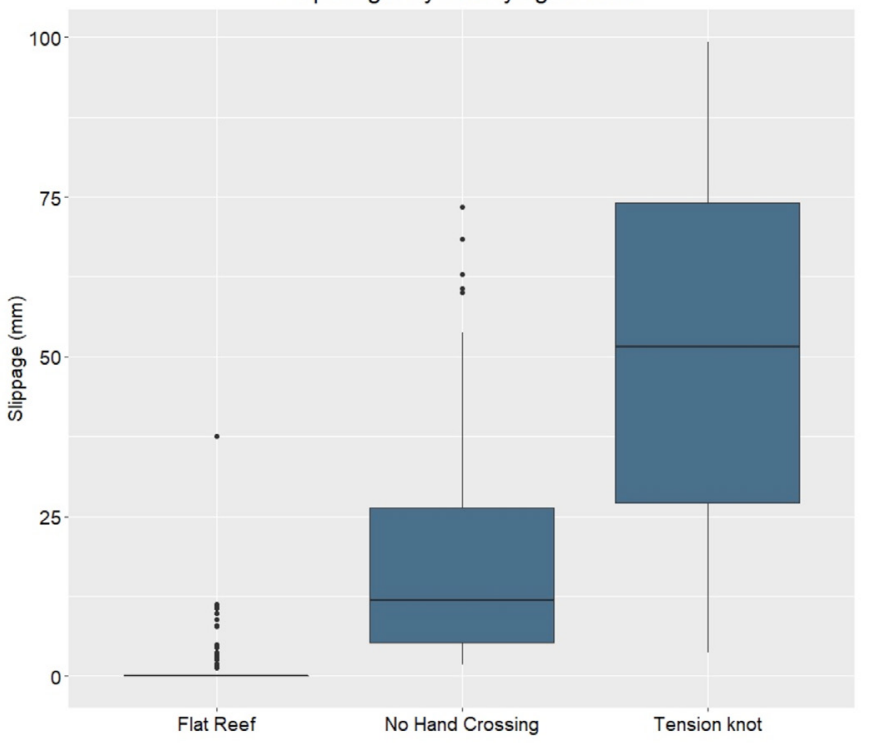

Figure 8 Boxplot displaying the slippage length, and median length and interquartile range ofslippage, in $\mathrm{mm}$ by knot tying method.

alternately crossing the knot (NHCK) $(112.8 \%, 95 \%$ CI $94.3 \%$ to $131.4 \%, 18.5 \mathrm{~mm}, 95 \%$ CI 15.5 to $21.5 \mathrm{~mm}$ ), (table 2, figure 8)

Of the 90 knots tied with each material, the following numbers and proportions of knots slipped on testing: 2/0 polyglactin (Vicryl) $71(78.9 \%), 4 / 0$ poliglecaprone 25 (Monocryl) 60 (66.7\%), 3/0 PDS $63(70.0 \%)$ and 1 nylon (Ethilon) $70(77.8 \%)$ (table 2). Similar proportions of the larger suture materials, 2/0 polyglactin (Vicryl) and 1 nylon (Ethilon), slipped on testing. The proportions of knots tied with the smaller diameter suture materials, $4 / 0$ poliglecaprone 25 (Monocryl) and 3/0 PDS appeared to be smaller, but the differences were not significant.

The amounts of slippage of knots tied with the four different materials, as measured by a proportional increase in material held within the knot, did show that those tied with 1 nylon (Ethilon) slipped by a greater length, if they did slip (mean $213.0 \%$, 95\% CI $173.0 \%$ to $252.0 \%$ ), than those tied with the smaller diameter suture materials, $4 / 0$ poliglecaprone 25 (Monocryl) (mean 108.0\%, 95\% CI $73.8 \%$ to $142.0 \%$ ) and $3 / 0$ PDS (mean $119.0 \%, 95 \%$ CI $83.0 \%$ to $154.0 \%$ ). No solid conclusion could be drawn regarding the difference in slippage length with knots tied with 2/0 polyglactin (Vicryl) (table 2, figure 9).

We assessed whether the type of suture material would have an effect on the efficacy of each knot type, determining the mean slippage length within each method for each material type.

No knots tied with 4/0 poliglecaprone 25 (Monocryl) using the FRK technique slipped to any appreciable extent. We observed no significant difference between the lengths of slippage of FRK tied with the other three suture materials. Knots tied with 1 nylon (Ethilon) using the technique of not crossing your hands appropriately, and those tied while keeping the knot under tension, did

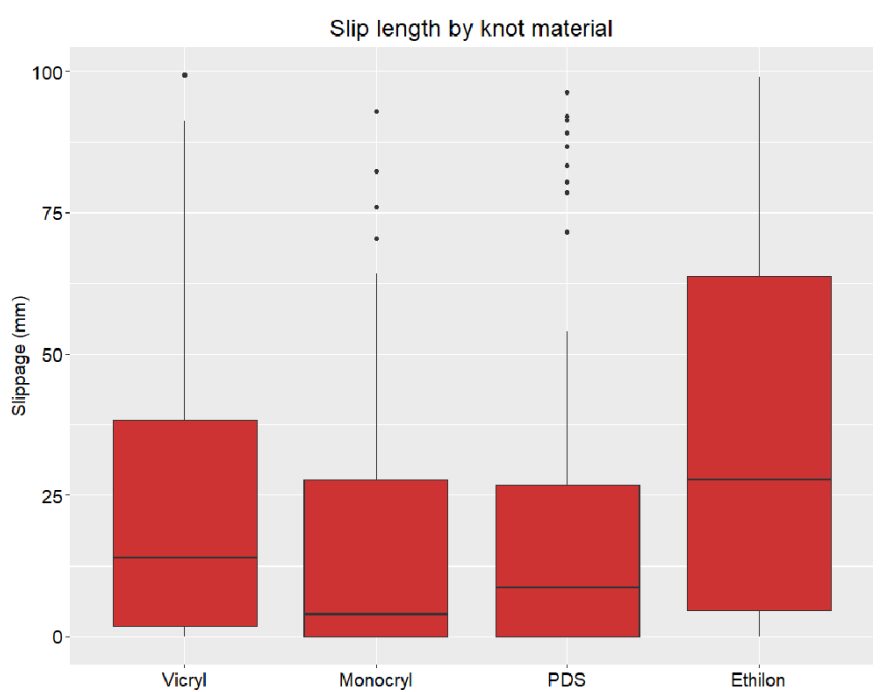

Figure 9 Box plot displaying lengths of slippage, and median slippage and IQR of slippage, for knots tied with eachsuture material. PDS, polydioxanone.

appear to slip more than knots tied with the same techniques, using the other three suture materials (table 3 , figure 10).

We believe this is likely to be due to this large monofilament suture being stronger and less likely to break under tension than smaller diameter suture materials. Knots tied with this material that then slip are less likely to break than those tied with the other materials (table 4).

\section{Knot breakage}

Of 360 knots tied, 284 broke on testing, with or without some degree of slippage, 76 slipped completely without breaking.

The proportion of knots that broke completely on testing, whether following some degree of slippage prior to breaking or not slipping at all, was significantly greater for those tied with an FRK technique $(0.99$, 95\% CI 0.98 to 1.00), than those tied with one hand holding the knot under tension (TK) $(0.56,95 \%$ CI 0.47 to 0.65$)$, and with one hand always moving in a downward direction (NHCK) $(0.82,95 \%$ CI 0.75 to 0.89$)$ One knot of 120 tied with an FRK technique did slip completely, but this compares favourably with 53 knots tied with one hand holding the knot under tension that slipped completely (TK), and 22 of those tied with one hand moving in a downward direction for all layers of the knot (NHCK) (table 5).

On assessing what proportions of knots tied using each of the four suture materials employed in this study, virtually all knots tied with $4 / 0$ poliglecaprone 25 (Monocryl) broke on testing $(87,96.7 \%)$. Fewer of those tied with $2 / 0$ polyglactin (Vicryl) $(74,82.2 \%)$ and $3 / 0$ PDS $(76,84.4 \%)$ broke, and only just over half of those tied with 1 nylon (Ethilon) broke $(47,52.2 \%)$. (table 4 )

\section{Length of suture material included in each knot type prior to testing}

The mean lengths of suture material incorporated into knots, that is the length of material in the loop tied 
Table 3 Number of knots tied with each suture material, using each technique and length of slippage MM

\begin{tabular}{|c|c|c|c|c|c|c|}
\hline Method & Material & $\begin{array}{l}\text { No of knots tied } \\
\text { with technique } \\
\text { and suture } \\
\text { material }\end{array}$ & $\begin{array}{l}\text { No of knots that } \\
\text { slipped }\end{array}$ & Mean (mm) & Lower $\mathbf{C l}$ & Upper Cl \\
\hline Flat Reef Knot (FRK) & 2/0 polyglactin (Vicryl) & 30 & $11(36.7 \%)$ & 1.4 & 0.4 & 2.4 \\
\hline FRK & $\begin{array}{l}\text { 4/0 poliglecaprone } 25 \\
\text { (Monocryl) }\end{array}$ & 30 & $0(0 \%)$ & 0.0 & 0.0 & 0.0 \\
\hline FRK & 1 nylon (Ethilon) & 30 & $10(33.3 \%)$ & 3.3 & 0.5 & 6.0 \\
\hline $\begin{array}{l}\text { No Hand Crossing } \\
\text { Knot (NHCK) }\end{array}$ & 2/0 polyglactin (Vicryl) & 30 & $30(100 \%)$ & 19.9 & 15.1 & 24.8 \\
\hline NHCK & $\begin{array}{l}\text { 4/0 poliglecaprone } 25 \\
\text { (Monocryl) }\end{array}$ & 30 & $30(100 \%)$ & 7.1 & 2.5 & 11.7 \\
\hline TK & $\begin{array}{l}\text { Monocryl4/0 } \\
\text { poliglecaprone } 25 \\
\text { (Monocryl) }\end{array}$ & 30 & $30(100 \%)$ & 39.6 & 31.7 & 47.5 \\
\hline TK & 3/0 PDS & 30 & $30(100 \%)$ & 43.4 & 32.1 & 54.6 \\
\hline TK & 1 nylon (Ethilon) & 30 & $30(100 \%)$ & 68.3 & 62.2 & 74.4 \\
\hline
\end{tabular}

around the hooks held by the knot was measured for all 360 knots. The average lengths of suture material included in the loop for TK tension (mean $17.0 \mathrm{~mm}$, $95 \% \mathrm{CI} 16.3$ to $17.7 \mathrm{~mm}$ ), and those tied without the operator crossing their hands (NHCK mean $16.3 \mathrm{~mm}$ $95 \%$ CI 15.9 to $16.7 \mathrm{~mm}$ ) were significantly lower than that for (FRK mean $25.1 \mathrm{~mm}, 95 \%$ CI 24.2 to $26.0 \mathrm{~mm}$ ). (table 6). This would suggest that that the first two types

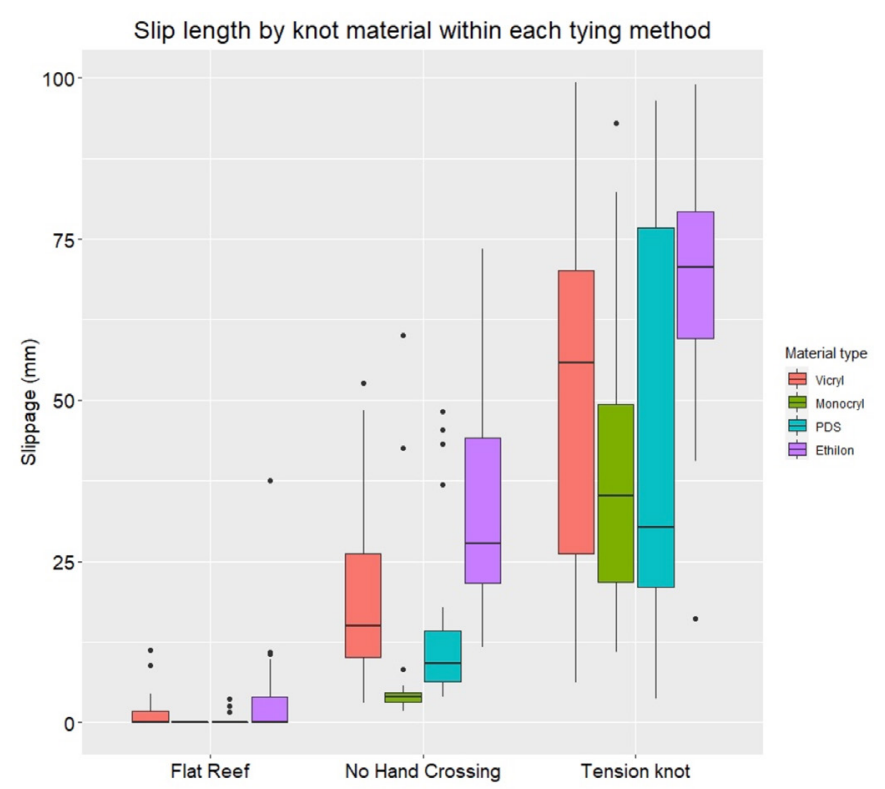

Figure 10 Box plot of slip lengths of knots tied with each of the three techniques, using the four suture materials. PDS, polydioxanone. of knot may tighten more than anticipated, once they are initially formed, in comparison to FRK, and this further tightening may potentially produce undue tissue tension, which may affect tissue viability and healing.

\section{DISCUSSION}

The ability to tie a reliable and secure knot has always been, and remains, an essential skill for any surgeon, veterinary surgeon, or clinician engaged in any practical clinical discipline, ${ }^{1}$ and even with the advent of new technological aids and robotic machines to aid our surgical practice ${ }^{58-60}$ formation of a secure knot remains an essential part of an individual surgeon's or practitioner's craft. In our study, the majority of knots tied with an FRK technique were secure, with no slippage at all, and of those that did slip, the proportional slip was small. Knots tied with this technique, preformed carefully to ensure equal and opposite lengths of suture were entwined, could be considered to be reliable. Those tied with the other two techniques were not secure. All of the latter two types slipped, with all of the materials used, and all tied by each surgeon group.

The degree to which these knots tied with the other two techniques slipped, was remarkable, particularly those tied with one hand maintaining tension on the knot at all times (table 1, figure 8). Those tied with a technique that mimicked a surgeon failing to cross their hands appropriately slipped by more than $100 \%$, those tied by a technique mimicking a surgeon maintaining tension on the knot throughout its formation, as may occur tying in a 
Table 4 Number and proportion of knots tied using each suture material that broke on testing

\begin{tabular}{|c|c|c|c|}
\hline Suture material used for knot formation & No of knots formed & $\begin{array}{l}\text { No of knots that broke } \\
\text { on testing }\end{array}$ & $\begin{array}{l}\text { Proportion of knots formed } \\
\text { that broke on testing } \%\end{array}$ \\
\hline 2/0 polyglactin (Vicryl) & 90 & 74 & 82.2 \\
\hline 3/0 polydioxanone & 90 & 76 & 84.4 \\
\hline One nylon (Ethilon) & 90 & 47 & 52.2 \\
\hline
\end{tabular}

difficult location or at depth, ${ }^{1314261}$ more than $300 \%$. In contrast, the mean degree of slip of knots tied with an FRK technique was markedly less, $6.3 \%$. The small mean result may have been influenced by the large denominator, 120 knots in total, but we did observe that the majority of those FRK that did slip only slipped by a small margin.

Though we observed that knots tied with the largest diameter suture material, 1 nylon (Ethilon), once they did slip, appeared to slip to a greater extent than those tied with the other materials, (tables 2 and 3, figures 9 and 10), the proportion of knots using this material that slipped was not markedly greater (table 2). This apparent difference between suture materials was probably due to the inherent greater strength of the larger suture in comparison to the others; only $52 \%$ of knots tied with this larger suture broke on testing. (table 4).

All knots tied with 4/0 poliglecaprone 25 (Monocryl), using the FRK technique, held firm and broke on testing, without slippage (table 3, figure $10 .^{62}$ We can make no other conclusions regarding results of individual suture materials, only that the technique used markedly influenced the security and reliability of the knot formed, for all the materials used in this study. (tables 1, 3 and 5, figures 8 and 10).

Knots tied with the techniques of maintaining tension on the knot with one hand, and those tied by an operator failing to cross their hands appropriately, included less material in the loop held by the knot than those tied with an FRK technique (table 6 ). This may be due to knots tied with these techniques being more prone to slip, and these knots may have slipped more tightly again once the first throw was laid, so less material would be subsequently left within the loop secured by the knot.
If such knots can slip more tightly again, following initial formation of the knot, this may lead to undue tension being applied to a suture, and this, in turn, could lead to undue and unintended tension on the suture. This may have a detrimental effect on tissue healing, such as a bowel or ureteric anastomosis, or wound closure. Insecure knots may cause harm not only from loosening and slipping post formation, but also from squashing and crushing tissue inadvertently during their initial formation.

The salient result was the marked difference in the integrity of knots tied with an FRK technique in comparison to those using the other two techniques, and such was the degree of slippage that we should probably consider knots tied with these two other methods dangerous.

Why did these dramatic knot failures occur in our study? Was this a failure of the design of the study, are our results clinically relevant; are we using the wrong type of knot; are modern suture materials too slippery for secure knot formation; and if we accept there is a potential widespread problem with the security of surgical knots in surgical practice in general, can we overcome the problem, or rely on technology to find other ways of securing haemostasis, anastomoses and closure of wounds, other than TK on a suture, ${ }^{565-60}$ ?

We would suggest that secure and reliable surgical knots can be consistently made with the simple reef knot with modern materials, provided we employ a meticulous technique, for each and every layer, or throw, of each knot. ${ }^{4047}$

The simple reef knot has been the most commonly used, and taught, surgical knot. The 'Hercules knot', or square knot, has been recorded to have been used in surgical practice in Greece in the first century $\mathrm{AD}$, and the square knot, or reef knot has probably been used in general for 2000 years, ${ }^{63-65}$ The reef knot, tied appropriately, was used to hold heavy,

Table 5 Number of knots tied using each knot technique that slipped and broke and slipped completely, and number and proportion that broke on testing

\begin{tabular}{|c|c|c|c|c|c|c|}
\hline $\begin{array}{l}\text { Method of } \\
\text { formation of } \\
\text { square reef knot }\end{array}$ & $\begin{array}{l}\text { Total no of } \\
\text { knots formed } \\
\text { that slipped }\end{array}$ & $\begin{array}{l}\text { No of knots } \\
\text { that slipped } \\
\text { and then } \\
\text { broke }\end{array}$ & $\begin{array}{l}\text { No of knots } \\
\text { that slipped } \\
\text { completely } \\
\text { without any } \\
\text { suture breakage }\end{array}$ & $\begin{array}{l}\text { Proportion of } \\
\text { knots formed that } \\
\text { broke and did not } \\
\text { slip completely }\end{array}$ & $\begin{array}{l}\text { 95\% lower } \mathrm{Cl} \text { of } \\
\text { proportion }\end{array}$ & $\begin{array}{l}95 \% \text { upper } \\
\mathrm{Cl} \text { of } \\
\text { proportion }\end{array}$ \\
\hline Flat reef knot & 24 & 23 & 1 & 0.99 & 0.98 & 1.00 \\
\hline $\begin{array}{l}\text { No hand-crossing } \\
\text { knot }\end{array}$ & 120 & 98 & 22 & 0.82 & 0.75 & 0.89 \\
\hline
\end{tabular}


Table 6 Mean lengths of suture material incorporated into loop holding hooks in test bed, for each type of knot method

\begin{tabular}{lllll}
$\begin{array}{l}\text { Method of formation of square reef } \\
\text { knot }\end{array}$ & $\begin{array}{l}\text { Total no of knots } \\
\text { formed }\end{array}$ & $\begin{array}{l}\text { Mean length of suture material } \\
\text { incorporated into loop held by knot } \mathbf{~ m m}\end{array}$ & $\begin{array}{l}\mathbf{9 5 \%} \text { lower } \\
\text { Cl of mean }\end{array}$ & $\begin{array}{l}\mathbf{9 5 \%} \text { upper } \mathbf{~ C l} \\
\text { of mean }\end{array}$ \\
\hline Flat reef knot & 120 & 25.1 & 24.2 & 26.0 \\
\hline No hand-crossing knot & 120 & $\mathbf{1 6 . 3}$ & $\mathbf{1 5 . 9}$ & $\mathbf{1 6 . 7}$ \\
\hline Knot tied under tension & 120 & $\mathbf{1 7 . 0}$ & $\mathbf{1 6 . 3}$ & $\mathbf{1 7 . 7}$ \\
\hline
\end{tabular}

Results in bold are significantly different.

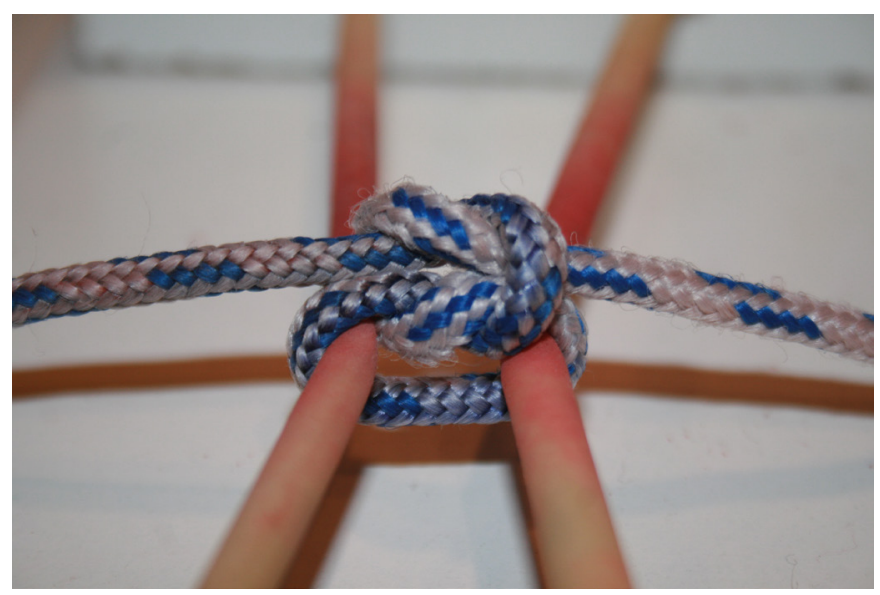

Figure 11 Flat reef knot prior to being unreefed.

large wet sails in place, even in the worst of stormy weather, as recommended in sailing texts from the $18^{\text {th }}$ century, and described in instruction books for sailors in the 18th and 19th centuries. ${ }^{66-68}$ If such a simple knot can control such a heavy burden in these difficult circumstances, and has been used so extensively, and for so long in surgical practice, ${ }^{163}$ why did we observe such a problem with those tied with two techniques in this study, and failure rates of $24 \%-80 \%$ reported for reef knots tied by experienced surgeons and in studies on teaching knots to students and junior surgeons ${ }^{15769}$ ? The answer may lie in how reef knots are untied, ${ }^{70}$ and in the nature of modern surgical suture materials.

Sailors can untie, or 'unreef' a knot by pulling on one strand of the knot, this will change the configuration of the

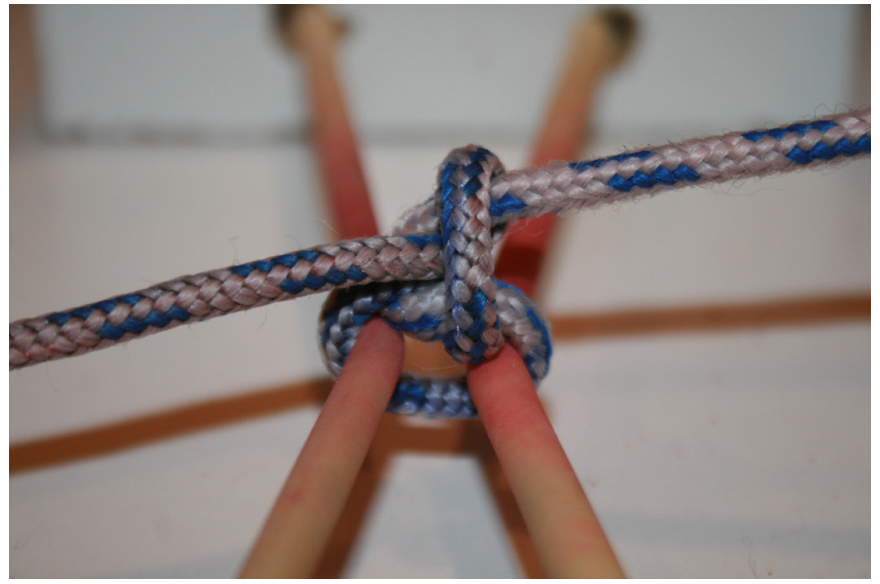

Figure 12 Initial effect of pulling on one end of reef knot causing initial loosening.

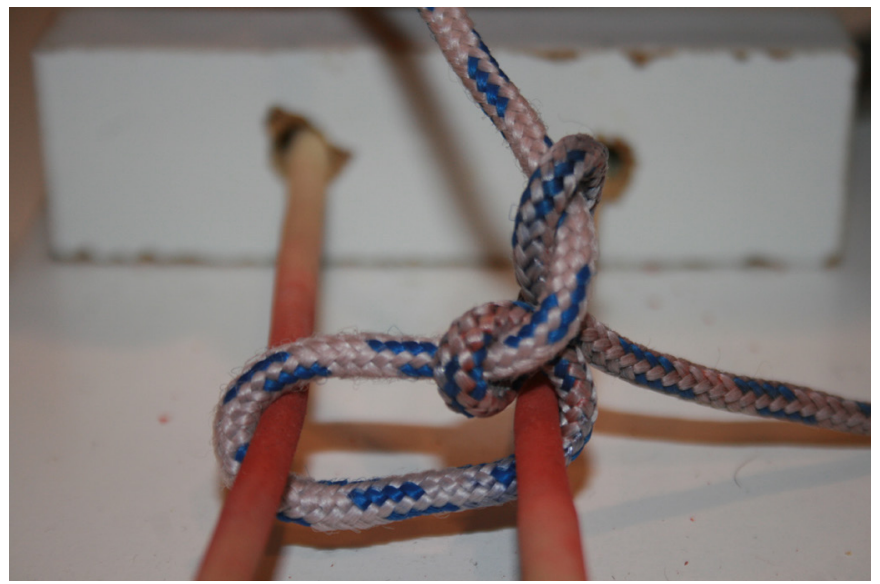

Figure 13 Final effect of pulling on one end of reef knot leading to loosening of knot.

knot so that there will be unequal amounts of the two strands of rope in the knot, and one strand can adopt a straight configuration reducing its frictional surface in contact with the other strand, so that it can be undone (figures 11-13). ${ }^{4470}$

The two knot techniques that produced a failure rate of $100 \%$ would have laid unequal amounts of the two suture strands within the knot, reducing the friction between the two strands (figures 2 and 4).

A knot relies on friction between the strands of material placed in mutual apposition within the knot, ${ }^{144} 4571$ and this in turn will rely on the natural friction, or lack of slipperiness, of the suture material, and how well the two strands are laid together to produce as much mutual contact between them. The FRK technique would potentially lead to as much contact as possible between the two strands, provided care is taken to ensure equal amounts of material are placed in the knot (figures 1 and 7). What we did observe, during the course of the study, and on observation of videos of the knots we formed, was that even if participants took as much care as possible in forming the FRK, small twists in the material could lead to a less than perfect apposition of the suture strands at the final laying down of the knot, leading to unequal strand lengths in the final knot. This may make these particular knots less resistant to slipping on testing, and could explain why a proportion of knots tied with our FRK technique slipped, and why some knots tied by senior surgeons in other studies failed. ${ }^{40} 4251$

Knots rely on friction between the strands of material laid in the knot, and the material must have a level of surface friction sufficient to allow knots to hold. ${ }^{145}$ Though more 
modern suture materials would appear to more slippery, and pass through tissue less traumatically than older and traditional materials, even monofilament nylon has sufficient surface friction to allow a simple reef knot to hold. ${ }^{45}$

The study design was simple, relying on a winch applied to a weighing spring, to produce an incremental force to distract two metal hooks tied together with the four, dry, suture materials we tested. Other studies assessing different types of knots, rather than technique of knot formation, have validated the use of such simple techniques and equipment. ${ }^{2-81022} 28355772$ We would suggest that our conclusions on knot security are clinically valid; poor technique can lead to dramatically poor results.

What should we do in clinical practice? This study, and other studies that have compared different types of knots rather than the influence of technique on knot integrity, ${ }^{1-43}$ have demonstrated that a proportion of knots can slip. This is a small study, and should probably be viewed as a preliminary study, but the results are clear. Do we abandon using sutures and look at other methods relying on technology, such as stapling devices for all anastomoses, haemostatic devices for haemostasis and vessel control, and staple all wounds, ${ }^{56} 58-60$ or do we accept that technique and craft are essential for a successful outcome when forming knots, ${ }^{40} 51$ ? Relying on technology would be expensive, and limit our adaptability; we cannot produce sufficient tailor made technological solutions for all surgical eventualities we may encounter, and technology is intended to aid our craft and abilities, not replace it. Instead, we could improve our individual ability to lay secure, flat knots, in all circumstances and anatomical situations, and employ it universally. If a simple task as tying a secure knot can be so affected by technique, should we consider assessing the technique of all our manoeuvres and procedures?

\section{ARTICLE SUMMARY}

- The majority of knots tied with an FRK technique appeared to be secure.

- All knots tied with the other two techniques, with all materials, slipped on testing and slipped markedly.

- The length of suture material within loops held by FRK was greater than in those held by knots tied with the other two techniques, suggesting these latter two slipped tighter during knot formation

- Given the marked difference in the security of knots tied by the techniques studied, even though a relatively small number of knots were tied and assessed in this study, all clinicians and health professionals engaged in any invasive procedures should assess their knot tying techniques to ensure their knots are secure.

Collaborators Ethicon Greece kindly provided the suture materials requiredKonstantinos $\mathrm{G}$ Railis for filming and recording images of our study and initial data storage and film editingThe management team of IASO hospital Thessaly for provision of facilities, and support for this study Sarandos Kaptanis for his guidance on the historical context of surgical knots and advice on our initial drafting of this paperEthicon Greece kindly provided the suture materials required.
Contributors ED: main author, participant in experiments, statistical analysis, design of study, editing figures, data storage and processing. SS: edited paper, participant in experiments, design of study with main author, photography and design of figures. ES: facilitator of location for study, participant in experiments, data storage and handling, statistical analysis, participant in design of study and academic guidance on handling on analysis of data. EPo: edited paper, participant in experiments, sourcing materials and equipment for experiments, image capture for figures. IP: edited paper, participant in experiments, image capture for figures. EPa: provision of equipment for experiments and measurements, edited paper, participant in experiments, image capture for figures. LS: data handling and management, detailed statistical analysis and advice on suitable models of data assessment, completion of plot diagrams, editing paper. DZ: provision of location, equipment and resources for study, participation in design of study and data analysis, academic advice and guidance.

Funding The authors have not declared a specific grant for this research from any funding agency in the public, commercial or not-for-profit sectors.

Competing interests None declared.

Patient consent for publication Not required.

Ethics approval The trustees of IASO hospital, Larissa, Greece, gave their approval and support for this study. The participants who performed the knots are the authors of this study and have given approval for the results of their knots to be published.

Provenance and peer review Not commissioned; externally peer reviewed.

Data availability statement Data are available on reasonable request. We would be delighted to share and publish our raw data.

Open access This is an open access article distributed in accordance with the Creative Commons Attribution Non Commercial (CC BY-NC 4.0) license, which permits others to distribute, remix, adapt, build upon this work non-commercially, and license their derivative works on different terms, provided the original work is properly cited, appropriate credit is given, any changes made indicated, and the use is non-commercial. See: http://creativecommons.org/licenses/by-nc/4.0/.

ORCID iD

Eric Drabble http://orcid.org/0000-0002-6790-7032

\section{REFERENCES}

1 Taylor FW. Surgical knots. Ann Surg 1938;107:458-68.

2 Gillen AM, Munsterman AS, Hanson RR. In vitro evaluation of the size, knot holding capacity, and knot security of the Forwarder knot compared to square and surgeon's knots using large gauge suture. Vet Surg 2016;45:1034-40.

3 Gillen AM, Munsterman AS, Farag R, et al. In vitro evaluation of square and surgeon's knots in large gauge suture. Vet Surg 2017;46:297-305.

4 Dinsmore RC. Understanding surgical knot security: a proposal to standardize the literature. J Am Coll Surg 1995;180:689-99.

5 Fong EDM, Bartlett ASR, Malak S, et al. Tensile strength of surgical knots in abdominal wound closure. ANZ J Surg 2008;78:164-6.

6 Jianmongkol S, Hooper G, Kowsuwon W, et al. A comparative biomechanical study of the looped square slip knot and the simple surgical knot. Hand Surg 2006;11:93-9.

7 Brouwers JE, Oosting H, de Haas D, et al. Dynamic loading of surgical knots. Surg Gynecol Obstet 1991;173:443-8.

8 Kadirkamanathan SS, Shelton JC, Hepworth CC, et al. A comparison of the strength of knots tied by hand and at laparoscopy. J Am Coll Surg 1996;182:46-54.

9 Tera $\mathrm{H}$, Aberg $\mathrm{C}$. Tensile strengths of twelve types of knot employed in surgery, using different suture materials. Acta Chir Scand 1976;142:1-7.

10 Trimbos JB. Security of various knots commonly used in surgical practice. Obstet Gynecol 1984;64:274-80.

11 Trimbos JB, Van Rijssel EJC, Klopper PJ. Performance of sliding knots in monofilament and multifilament suture material. Obstetrics \& Gynecology 1986;68:425-30.

12 Komatsu F, Mori R, Uchio Y. Optimum surgical suture material and methods to obtain high tensile strength at knots: problems of conventional knots and the reinforcement effect of adhesive agent. $J$ Orthop Sci 2006;11:70-4.

13 Schaaf O, Glyde M, Day RE. In vitro comparison of secure Aberdeen and square knots with plasma- and fat-coated polydioxanone. Vet Surg 2010;39:553-60. 
14 James JD, Wu MM, Batra EK, et al. Technical considerations in manual and instrument tying techniques. J Emerg Med 1992;10:469-80.

15 Rosin E, Robinson GM. Knot security of suture materials. Vet Surgery 1989;18:269-73.

16 Lee ACH, Fahmy RRR, Hanna GB. Objective evidence for optimum knot configuration. World J Surg 2008;32:2736-41.

17 Abbi G, Espinoza L, Odell T, et al. Evaluation of 5 knots and 2 suture materials for arthroscopic rotator cuff repair: very strong sutures can still slip. Arthroscopy 2006;22:38-43.

18 Shaw AD, Duthie GS. A simple assessment of surgical sutures and knots. J R Coll Surg Edinb 1995;40:388-91.

19 van Rijssel EJ, Trimbos JB, Booster MH. Mechanical performance of square knots and sliding knots in surgery: comparative study. $A m \mathrm{~J}$ Obstet Gynecol 1990;162:93-7.

20 Stott PM, Ripley LG, Lavelle MA. The ultimate Aberdeen knot. Ann R Coll Surg Engl 2007;89:713-7.

21 Tidwell JE, Kish VL, Samora JB, et al. Knot security: how many throws does it really take? Orthopedics 2012;35:e532-7.

22 Avoine X, Lussier B, Brailovski V, et al. Evaluation of the effect of 4 types of knots on the mechanical properties of 4 types of suture material used in small animal practice. Can $J$ Vet Res 2016;80:162-70.

23 Sedlack JD, Williams VM, DeSimone J, et al. Laparoscopic knot security. Surg Laparosc Endosc 1996;6:144-6.

24 Evin HA, Bilden TT, Noonan BC, et al. A biomechanical comparison of varying base knot configurations with different Overhand/Underhand combinations of reversing Half-Hitches on alternating posts after basic instructional training. lowa Orthop $J$ 2019;39:131-40.

25 Lutchman CR, Leung LH, Moineddin R, et al. Comparison of tensile strength of slip knots with that of 3-1-1 knots using 10-0 nylon sutures. Cornea 2014;33:414-8.

26 Dueñas-Garcia OF, Sullivan GM, Leung K, et al. Knot integrity using different suture types and different knot-tying techniques for reconstructive pelvic floor procedures. Int Urogynecol J 2018;29:979-85.

27 Lo IKY, Burkhart SS, Chan KC, et al. Arthroscopic knots: determining the optimal balance of loop security and knot security. Arthroscopy 2004;20:489-502.

28 Kuptniratsaikul S, Weerawit $\mathrm{P}$, Kongrukgreatiyos K, et al. Biomechanical comparison of four sliding knots and three highstrength sutures: loop security is much different between each combination. J Orthop Res 2016;34:1804-7.

29 Meyer DC, Bachmann E, Lädermann A, et al. The best knot and suture configurations for high-strength suture material. An in vitro biomechanical study. Orthop Traumatol Surg Res 2018;104:1277-82.

30 Lo IKY, Ochoa E, Burkhart SS. A comparison of knot security and loop security in arthroscopic knots tied with newer high-strength suture materials. Arthroscopy 2010;26:S120-6.

31 Romeo A, Fernandes LF, Cervantes GV, et al. Which knots are recommended in laparoscopic surgery and how to avoid insecure knots. J Minim Invasive Gynecol 2020;27:1395-404.

32 Schneider AM, Pedowitz RA, Evans DA. Validation of the fast workstation as an objective evaluator of hand-tied surgical knots. Simul Healthc 2019;14:29-34.

33 Silver E, Wu R, Grady J, et al. Knot Security- how is it affected by suture technique, material, size, and number of throws? J Oral Maxillofac Surg 2016;74:1304-12.

34 van Leeuwen N, Trimbos JB. Strength of sliding knots in multifilament resorbable suture materials. Gynecol Surg 2012;9:433-7.

35 Sanders RE, Kearney CM, Buckley CT, et al. Knot security of 5 metric (USP 2) sutures: influence of knotting technique, suture material, and incubation time for 14 and 28 days in phosphate buffered saline and inflamed equine peritoneal fluid. Vet Surg 2015;44:723-30.

36 Good MM, Good LB, Mclntire DD, et al. Surgical knot integrity: effect of suture type and caliber, and level of residency training. J Surg Educ 2013;70:156-60.

37 Ind TE, Shelton JC, Shepherd JH. Influence of training on reliability of surgical knots. BJOG 2001;108:1013-6.

38 Zimmer CA, Thacker JG, Powell DM, et al. Influence of knot configuration and tying technique on the mechanical performance of sutures. J Emerg Med 1991;9:107-13.

39 Ching SS, Mok CW, Koh YX, et al. Assessment of surgical trainees quality of knot-tying. J Surg Educ 2013;70:48-54.

40 Batra EK, Franz DA, Towler MA, et al. Influence of surgeon's tying technique on knot security. J Appl Biomater 1993;4:241-7.

41 Muffly TM, Cook C, Distasio J, et al. Suture end length as a function of knot integrity. J Surg Educ 2009;66:276-80
42 Davis DA, Pellowski DM, Rawdon EJ. All monofilament knots assume sliding conformation in vivo. Dermatol Surg 2013;39:729-33.

43 Annunziata CC, Drake DB, Woods JA, et al. Technical considerations in knot construction. Part I. continuous percutaneous and dermal suture closure. J Emerg Med 1997;15:351-6.

44 Maddocks JH, Keller JB. Ropes in equilibrium. SIAM J Appl Math 1987;47:1185-200.

45 Crowell. The physics of knots. Available: http://www.lightandmatter. com/article/knots.htm

46 Ivy JJ, Unger JB, Hurt J, et al. The effect of number of throws on knot security with nonidentical sliding knots. Am J Obstet Gynecol 2004;191:1618-20.

47 Ivy JJ, Unger JB, Mukherjee D. Knot integrity with nonidentical and parallel sliding knots. Am J Obstet Gynecol 2004;190:83-6.

48 Trimbos JB, Van Rijssel EJ, Klopper PJ. Performance of sliding knots in monofilament and multifilament suture material. Obstet Gynecol 1986;68:425-30.

49 Muffly TM, Kow N, lqbal I, et al. Minimum number of throws needed for knot security. J Surg Educ 2011;68:130-3.

50 RCS Eng Education Department. Participants' handbook of the sixth intercollegiate Basic Surgical Skills course, 2017.

51 Franz DA, Batra EK, Morgan RF, et al. A portable tensiometer for assessing KNOT-TYING technique. Orthopedics 1995;18:555-8.

52 Hanypsiak BT, DeLong JM, Simmons L, et al. Knot strength varies widely among expert arthroscopists. Am J Sports Med 2014:42:1978-84.

53 Babetty Z, Sümer A, Altintaș S, et al. Changes in knot-holding capacity of sliding knots in vivo and tissue reaction. Arch Surg 1998:133:727-34.

54 Thacker JG, Rodeheaver G, Kurtz L, et al. Mechanical performance of sutures in surgery. Am J Surg 1977;133:713-5.

55 Fischer L, Bruckner T, Müller-Stich BP, et al. Variability of surgical knot tying techniques: do we need to standardize? Langenbecks Arch Surg 2010;395:445-50.

56 Burton AF, Horstman C, Mason DR. Tensions generated in a lateral fabellotibial suture model. Comparison of methods of application of tension, fixation of tension and suture material. Vet Comp Orthop Traumatol 2015;28:391-400.

57 Muffly TM, Espaillat-Rijo LM, Edwards AM, et al. Operating room fatigue: is your twentieth surgical knot as strong as your first? J Surg Educ 2012;69:215-7.

58 Li H, Wei Y, Lei W. Laparoscopic extended left hemi-hepatectomy plus caudate lobectomy for caudate lobe hepatocellular carcinoma. J Gastrointest Surg 2019;23:617.

59 Tharakan SJ, Hiller D, Shapiro RM, et al. Vessel sealing comparison: old school is still hip. Surg Endosc 2016;30:4653-8.

60 Nota CL, Molenaar IQ, Borel Rinkes IH, et al. Robotic liver resection of segment 7: a step-by-step description of the technique. Surg Oncol 2020;34:206-7.

61 Kim SH, Glaser D, Doan J, et al. Loop securities of arthroscopic sliding-knot techniques when the suture loop is not evenly tensioned. Arthroscopy 2013;29:1380-6.

62 Trimbos JB, Niggebrugge A, Trimbos R, et al. Knotting abilities of a new absorbable monofilament suture: poliglecaprone 25 (Monocryl). Eur J Surg 1995;161:319-22.

63 Hage JJ. Heraklas on knots: sixteen surgical nooses and knots from the first century A.D. World J Surg 2008;32:648-55.

64 Palazzo F. Knot tying, ligatures, and suturing. fundamentals of general surgery. Springer, 2018: P50.

65 Przytycki JH. "Knots, low-dimensional topology and applications". Hellas: International Olympic Academy Greece, 2016: 115-9.

66 Steel D. The elements and practice of rigging and seamanship. London, 1794: P183.

67 Darcy L. The Young Sea Officer's Sheet Anchor. $2^{\text {nd }}$ edition. Mineola. NY: Dover Publications, 1998: 83

68 Dana RH. The Seaman's Friend: A Treatise on Practical Seamanship 1879 (14th revised and corrected ed. Mineola NY: Dover, 1997: P49.

69 Miller JR, Deeken CR, Ray S, et al. Expanded polytetrafluoroethylene for chordal replacement: preventing knot failure. Ann Thorac Surg 2015;100:2325-9.

70 Petit P. The square knot (revisited) in, why knot?: how to tie more than sixty ingenious, useful, beautiful, lifesaving, and secure knots! Harry N Abrams, 2013: 80-3.

71 Gupta BS, Wolf KW, Postlethwait RW. Effect of suture material and construction on frictional properties of sutures. Surg Gynecol Obstet 1985;161:12-26.

72 Stone IK, von Fraunhofer JA, Masterson BJ. A comparative study of suture materials: chromic gut and chromic gut treated with glycerin. Am J Obstet Gynecol 1985;151:1087-93. 